EXEMPLARIa Classica

Journal of Classical Philology

16, 2012, pp. 3-16

ISSN 1699-3225

\title{
LA LUCHA DEL PUEBLO POR LA LEY: UNA NUEVA PROPUESTA DE LECTURA DEL FRAGMENTO 22 B 44 DK DE HERÁCLITO
}

\author{
Raúl Caballero Sánchez \\ Universidad de Málaga \\ rcaballero@uma.es
}

SUMMARY

In this paper we discuss the main interpretations that scholars have given to Heraclitus's fragment B 44, and offer a new emendation on the grounds of what it is known about the political life of Ephesus and the role Heraclitus has played in it.

KEYWORDS

Textual criticism; Early Greek Philosophy; Heraclitus and politics

\section{RESUMEN}

En este trabajo discutimos las interpretaciones principales que se han dado al fragmento B 44 de Heráclito y proponemos una nueva lectura basada en lo que conocemos sobre la vida política de Éfeso y el papel que Heráclito desempeñó en ella.

Palabras Clave

Crítica textual; Filosofía griega arcaica; Heráclito y la política

Fecha de recepción: 11/06/2012

Fecha de aceptación y versión final: 15/09/2012

Al comienzo de su biografía de Heráclito, Diógenes Laercio ilustra la arrogancia y soberbia del sabio efesio citando algunas sentencias tomadas de su libro, entre las cuales se encuentra el fragmento $22 \mathrm{~B} 44 \mathrm{DK}^{1}$, que Diels

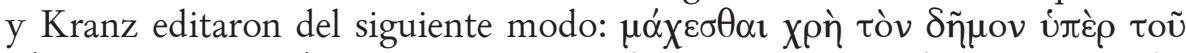

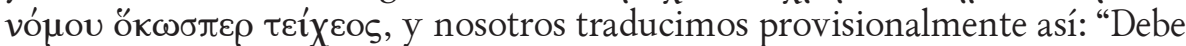
el pueblo luchar por la ley como si fuera su propia muralla".

${ }^{1}$ Cf. D.L. 9.2. En adelante, citamos los fragmentos de Heráclito, siguiendo la numeración de Diels-Kranz (DK), pero precedidos únicamente de la letra B. 
Pero en los manuscritos principales de Diógenes Laercio $\left(\mathbf{B} \mathbf{P}^{1} \mathbf{F}\right)^{2}$, el texto de este fragmento aparece en una versión más larga y difícil de entender:

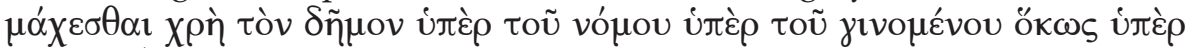

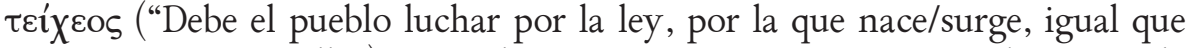
por su propia muralla”). Está claro que, por más que nos escudemos en la oscuridad proverbial del estilo de Heráclito, el fragmento, así leído, suscita en principio dos motivos de perplejidad:

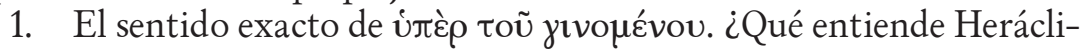
to por una "ley que va surgiendo, por una ley en devenir"? ¿Qué significa "luchar por la ley que se hace"? ¿Quizá que la ley es un proceso abierto y nunca acabado, siempre susceptible de nuevos desarrollos, que aseguren la cohesión de la comunidad ${ }^{5}$ Este punto lo discutiremos en detalle más adelante.

2. La triple ocurrencia de írép. Esta no es imposible, pero extraña en un autor de la economía expresiva de Heráclito. Además, esa doble repetición plantea el dilema de escoger entre las dos variantes del sintagma comparativo que cierra el fragmento, ambas ava-

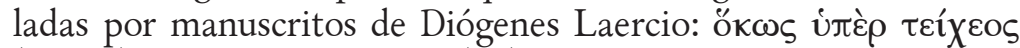

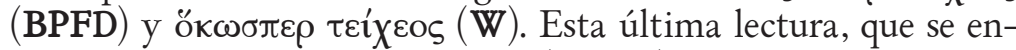
cuentra solo en el Vatic. Gr. 140 (s. XIV) y bien podría ser una conjetura de época paleóloga, ya fue en 1842 propuesta por Meineke ${ }^{6} \mathrm{y}$ ha sido acogida en el texto de la edición de Diels-Kranz y de otros muchos editores de Heráclito. La primera lectura (ökws

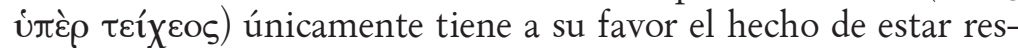
paldada por los manuscritos principales de Diógenes Laercio. Que,

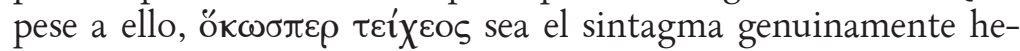
raclíteo lo aconsejan varios argumentos, oportunamente expues-

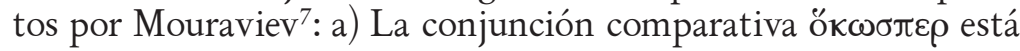

\footnotetext{
${ }^{2}$ Cf. M. Marcovich, Diogenes Laertius. Vitae philosophorum, I. Libri I-X, StuttgartLeipzig 1999, xii-xiv. Para un estudio casi exhaustivo y actualizado de la tradición manuscrita laerciana y de las relaciones genealógicas entre las distintas familias de manuscritos, cf. $\mathrm{T}$. Dorandi, Laertiana. Capitoli sulla tradizione manoscritta e sulla storia del testo delle Vite dei filosofi di Diogene Laerzio, Berlin-New York 2009, 49-124. Además de conservarse

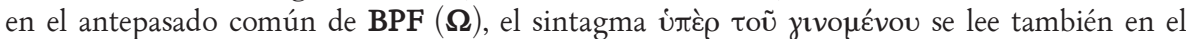
manuscrito $\mathrm{D}$, perteneciente a la llamada Recensio vulgata, cuyo prototipo $(\boldsymbol{\alpha})$, como apunta Dorandi, nació de la confluencia de $\mathbf{P}$ y el antepasado perdido de $\mathbf{F}(\gamma)$. En cambio, ese sintagma es omitido por las sucesivas manos que corrigieron $\mathbf{P}$ y sus respectivos apógrafos $\left(\mathbf{P}^{2}>\mathbf{Q} ; \mathbf{P}^{3}>\mathbf{C o}\right.$ W; $\left.\mathrm{P}^{4}>\mathrm{H}\right)$, así como por la Editio Frobeniana (1533) y su antígrafo $(\mathbf{Z})$.

${ }^{3}$ Así traduce S. Mouraviev, Heraclitea, III.3.B. Recensio. Fragmenta: les textes pertinents. Partie iii: Notes critiques, Sankt Augustin 2006, 53 (§ 2).

${ }^{4}$ Como traducen J. Bollack-H. Wismann, Héraclite ou la séparation, Paris 1972, 161.

${ }^{5}$ Cf. Bollack-Wismann, Héraclite, 162 (§ 3.2, § 3.3).

${ }^{6}$ A. Meineke, Delectus poetarum Anthologiae Graecae: cum adnotatione critica Augusti Meinekii, Berlin 1842, 173.

${ }^{7}$ Mouraviev, Heraclitea, III.3.B.iii: Notes critiques, 53 (§ 4).
} 
ampliamente atestiguada en Heráclito (B 1, B 29, B 51, B 67, B 79, B 90, B 114) y siempre lleva implícita la idea de comparación,

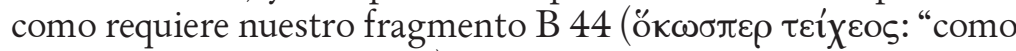
si fuera su propia muralla"). Precisamente, este "sema comparativo" se halla ausente de las dos únicas ocurrencias de öкws en Heráclito (B 1, B 51), donde se trata de un adverbio relativo de modo e introduce una interrogativa subordinada; b) La secuencia

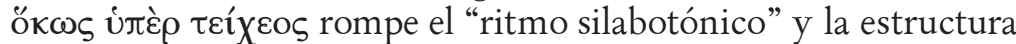
estrófica del fragmento; c) Desde el punto de vista estilístico y semántico, resulta injustificada la triple ocurrencia de úđé $\rho$. A estos argumentos nosotros añadiríamos otro, que tiene que ver con el

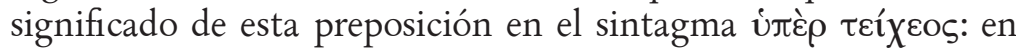
efecto, de este sintagma no se conserva ningún ejemplo anterior al siglo IV a.C. con el significado de "en defensa de la(s) muralla(s)", y solo se usa con el sentido de "por encima de la(s) muralla(s)" o "al otro lado de la(s) muralla(s)" ". Así pues, la hipótesis más pro-

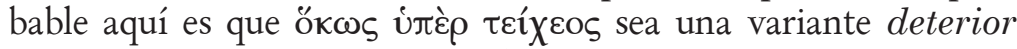

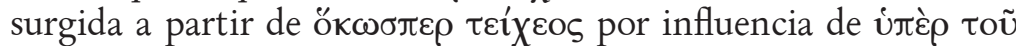

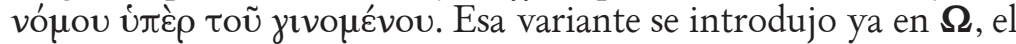
antepasado común de BPF, y de ahí pasó al texto de los códices principales de esta tradición: $\mathrm{BPF}$ y, más tarde, a través de $\boldsymbol{\alpha}, \mathrm{a} \mathrm{D}$.

A causa de estas dificultades, la mayoría de los estudiosos, siguiendo el

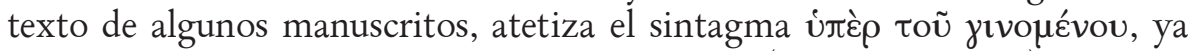

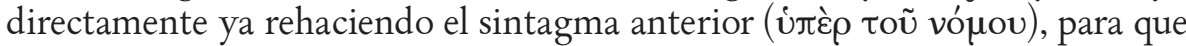

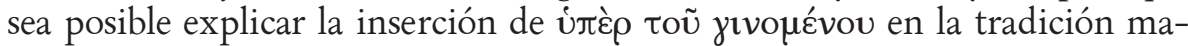

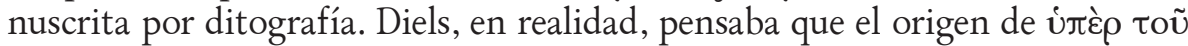

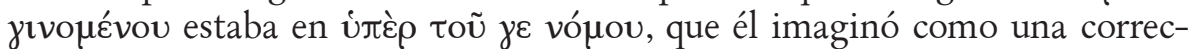
ción anónima del sintagma anterior, que se introdujo, malinterpretada, en el texto de Heráclito. En la estela de Diels, Marcovich, en su Editio maior, reconstruyó el primer sintagma en ritmo yámbico mediante la transposición

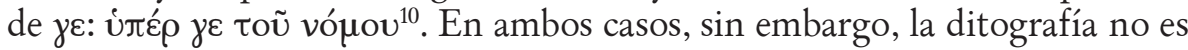
plena: aun admitiendo que los copistas pudieron malinterpretar vó ou $_{\text {como }}$

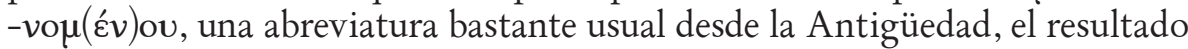

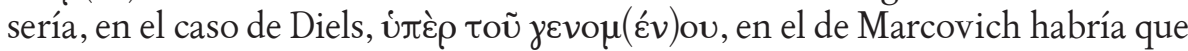
suponer además la transposición del artículo.

Otra posibilidad que, en nuestra opinión, merece la pena explorar es la de tomarse en serio el testimonio de los manuscritos. El primer estudioso

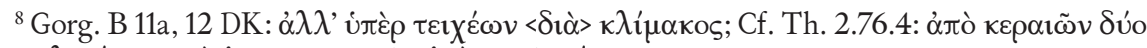

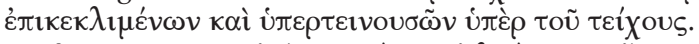

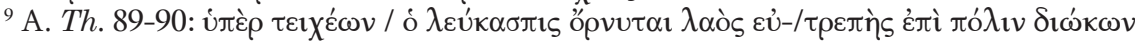
$<\pi \delta ́ \delta \alpha>$.

${ }^{10}$ La lectura de Marcovich fue abandonada en su Editio minor: cf. M. Marcovich, Eraclito. Frammenti, Firenze 1978, 367. 
que defendió el texto transmitido, Vollgraff, no ofrece rastro del sintagma de participio en su traducción latina del fragmento ("populum ius ac fas instar muri tueri oportet") ${ }^{11}$, pero ofrece hasta 61 ejemplos de la acepción que

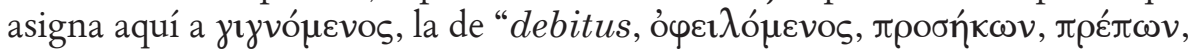
$\dot{\alpha} \rho \mu o ́ \tau \tau \omega v " 12$. Así pues, para Vollgraff el texto de Heráclito llamaría al pueblo a luchar por el conjunto de normas o leyes que le conciernen o competen, porque son las que se amoldan a su tradición y costumbres, sin aventurarse en peligrosos cambios o novedades ${ }^{13}$.

En parte deudora de la lectura de Vollgraff, pero con una interpretación distinta del sintagma de participio, Conche acoge también la lectura de los manuscritos principales de Diógenes Laercio: la ley por la que debe luchar el pueblo no es otra que la que ha superado la prueba del tiempo y de la costumbre, la que ha sido autentificada por la tradición; la ley de la polis atesora el sistema de valores y de reglas por las que la comunidad ha sabido mantenerse unida a lo largo de los siglos. De ahí la traducción propuesta por Conche: "pour celle qui existe", es decir, "pour la loi qui est sa loi, non pas pour une loi meilleure ou pour une loi idéale, mais pour sa loi telle qu'elle existe"14.

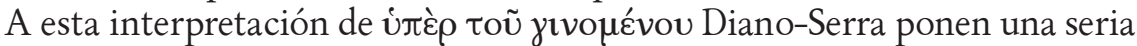
objeción: en griego, la ley que "existe" o "está vigente" en cada momento, no

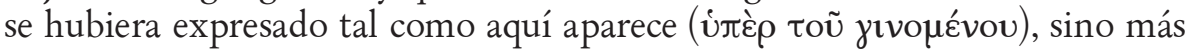
bien con el sintagma úं̇̀

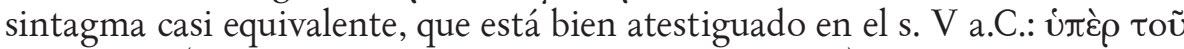
$\kappa \varepsilon \imath \varepsilon^{2} v v^{16}$ (de una ley 'estar fijada', 'estar establecida'). Incluso podría atisbarse, con propósitos diagnósticos, una lectura subyacente que hubiera dado

${ }^{11}$ G. Vollgraff, "De duobus Heracliti fragmentis”, Mnemosyne 45, 1917, 166-80 (180).

${ }^{12}$ Vollgraff, "De duobus Heracliti fragmentis", 168. La interpretación de Vollgraff se basa en ejemplos del s. IV a.C. en adelante, porque el único texto anterior que aduce en apoyo de

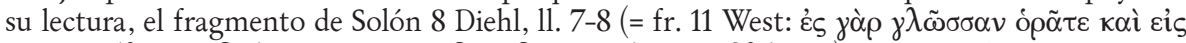

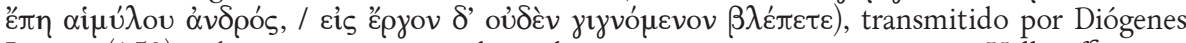
Laercio (1.52), es bastante controvertido y admite otras interpretaciones, como Vollgraff mismo reconocía. Así traduce este la última línea del fragmento: "opera virorum honesta non intuemini” (169). Es más probable, sin embargo, que Solón reprochase a los atenienses haberse dejado esclavizar por Pisístrato, "porque prestáis atención a la lengua y a las palabras de un hombre taimado, / mas no a ninguna de las acciones que está cumpliendo" (la traducción es nuestra).

${ }^{13}$ Cf. Vollgraff, "De duobus Heracliti fragmentis", 180.

${ }^{14}$ M. Conche, Héraclite. Fragments, Paris 1986, 222-3.

${ }^{15}$ C. Diano-G. Serra, Eraclito. I frammenti e le testimonianze, Milano 1980, 185-6.

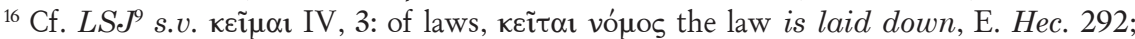

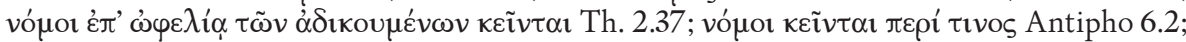

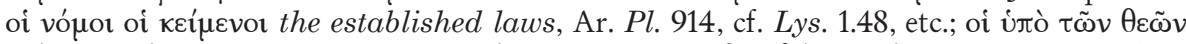

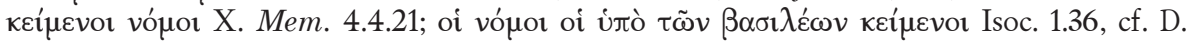

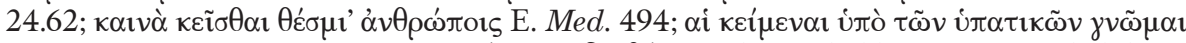

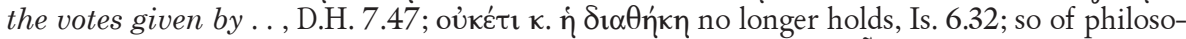

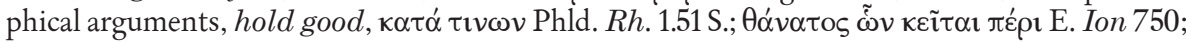

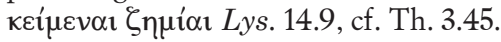




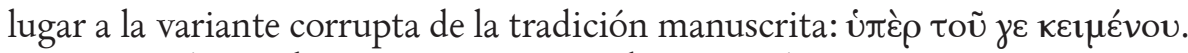
Pero no será este el camino que emprendamos aquí.

En su edición de Heráclito, Bollack-Wismann defienden por otros mo-

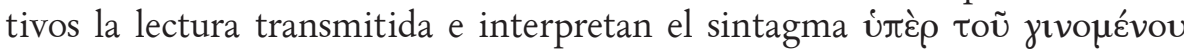
como un rasgo característico de la ley de la ciudad: a diferencia de la ley divina de B 114, que es única y no cambia nunca, la ley de la polis está sometida al devenir, como todas las demás cosas en Heráclito. En este sentido, la ley de la polis es "celle qui se fait" en cada momento histórico, dictada por necesidades concretas y cambiantes, y su dinamismo asegura la estabilidad simbolizada por la muralla física ${ }^{17}$. El principal problema con que tropieza esta interpretación es que sería muy difícil de explicar que Heráclito exhorte al pueblo de Éfeso a luchar por su propia ley, sea cual sea la respuesta que la comunidad haya dado en cada momento a las circunstancias cambiantes de la vida de la polis. Sería inverosímil imaginar a Heráclito expresando su anuencia a cualquier tipo de leyes. ¿Hubiera visto con buenos ojos que se implantaran en Efeso leyes que hubiesen dado un protagonismo destacado al pueblo en la toma de decisiones? Con esto chocan los fragmentos donde el Efesio desprecia abiertamente a la mayoría (B 2, B 17, B 29, B 104) o expresa una profunda desconfianza ante el criterio político de la muchedumbre (B 49). ¿Hubiera transigido con un régimen tiránico que hubiese concentrado todo el poder en una sola persona, situada por encima de la ley? Esto iría contra el mensaje contenido en el fragmento B 33, donde Heráclito recomienda la obediencia al consejo de un solo ciudadano si eso implica el mantenimiento de los usos normativos de la polis.

En una línea similar a Bollack-Wismann, pero sorteando esta objeción, se-

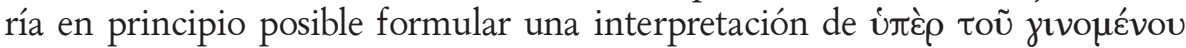
que pudiera salvar el texto transmitido sin forzar en exceso el significado de

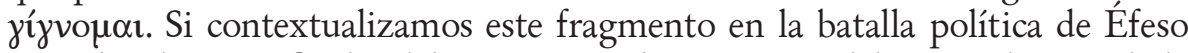
entre los decenios finales del s. VI a. C y los primeros del V, en el curso de la cual Heráclito recriminó amargamente a sus conciudadanos el destierro de Hermodoro, a quien consideraba "el más valioso de entre ellos" (B 121), las palabras del Efesio en B 44 podrían entenderse como una firme advertencia del filósofo

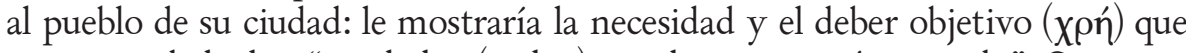
este tiene de luchar "por la ley (su ley), por la que se está gestando". Con estas palabras aludiría Heráclito a la obra legislativa que, como sabemos por otras fuentes, realizó Hermodoro en su ciudad nata ${ }^{18}$. En este supuesto, el fragmento se situaría antes del destierro de Hermodoro y su mensaje estaría muy cerca del que contiene el fragmento B 33: "Ley es también obedecer el consejo de uno

${ }^{17}$ Bollack-Wismann, Héraclite, $162(\S 3.2, \S 3.3)$.

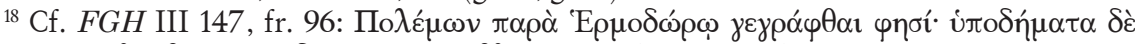

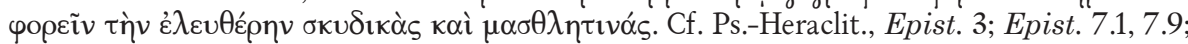
Epist. 8.1, 8.2; Epist. 9.1, 9.6. 
solo". Pero la dificultad más seria de este ensayo de lectura es que, para entender el fragmento, obliga al lector a sumergirse de lleno en las circunstancias concretas de la vida de Éfeso, cuando lo más probable es que Heráclito, con su peculiar estilo sentencioso, haya querido expresar aquí un mensaje más general, por más que este no sea ajeno a las luchas políticas de su tiempo.

Todas estas consideraciones aconsejan sin duda poner sobre la mesa nue-

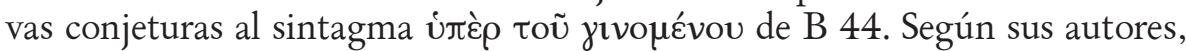
es necesario que la ley a la que se refiere Heráclito sea una ley bien fundada, para que merezca la pena que el pueblo luche por ella como si fuera la muralla

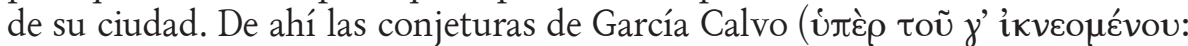

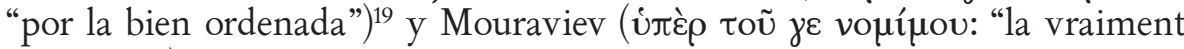
consacrée" ${ }^{20}$. En la línea ya apuntada antes, nosotros podríamos añadir ten-

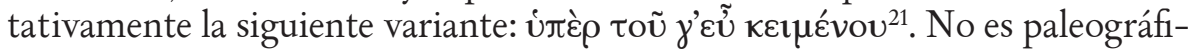
camente inverosímil y da un sentido similar al de las conjeturas ya mencionadas. Pero el talón de Aquiles de todas estas propuestas es el mismo: no añaden ningún aspecto lo suficientemente relevante o esencial como para justificar el esfuerzo de corregir el texto transmitido. El texto da prácticamente el mismo

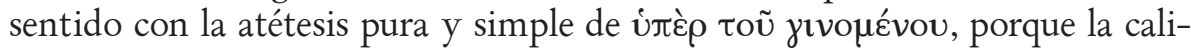
dad de la ley se da por supuesta si el pueblo ha de luchar por ella como lucha por su propia muralla.

Intentemos otras posibilidades de corregir el texto transmitido de B 44 . Para ello, convendría quizá delimitar con precisión el significado de las palabras-clave de este fragmento, que pivota sobre el binomio formado por tòv

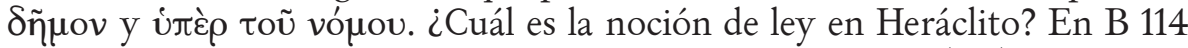
se afirma que "las leyes humanas se nutren todas de una sola (ley), la divina": tal ley no es sino la unidad de los contrarios. Esta declaración permitiría, a nuestro juicio, acotar el pensamiento político de Heráclito dentro de ciertos límites, sin dejar de estar subordinado a su pensamiento metafísico. Si la ciudad, como el universo, es un campo de batalla donde luchan fuerzas opuestas, el cometido de la ley de la polis no puede ser otro que asegurar o garantizar la unidad y cohesión del conjunto manteniendo las fuerzas en tensión, y esa tensión solo es efectiva si las fuerzas enfrentadas guardan entre sí una situación de equilibrio, por inestable que este sea ${ }^{22}$. Así ocurre en las célebres metá-

${ }^{19}$ A. García Calvo, Razón común. Edición crítica, ordenación, traducción y comentario de los restos del libro de Heraclito, Madrid 1985, 269-70.

${ }^{20}$ S. Mouraviev, Heraclitea, III.3.B. Recensio. Fragmenta: les textes pertinents. Partie $i$ : Textes, Traductions, Apparats I-III, Sankt Augustin 2006, 112-3.

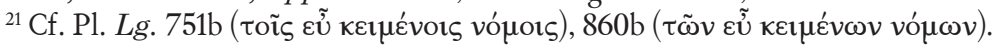

${ }^{22} \mathrm{La}$ relación entre la unidad de los contrarios, que es el pensamiento central de Heráclito, y sus ideas políticas está implícita en B 114: cf. Conche, Héraclite, 219; E. Lledó, "La lucha por la ley (Heráclito, fragmento B 44)”, en Memoria de la ética, Madrid 1994, 254-68 (265-6); R. Caballero, "Reflexiones sobre el concepto de 'publicación' en la Grecia Arcaica: el problema de los tratados en prosa”, Estudios Clásicos 127, 2005, 7-22 (18-9). 
foras del arco y la lira (B 51), cuya función es eficaz solo si entre sus elementos -la cuerda y los brazos del arco, la caja de la lira y sus cuerdas- se ejerce una tensión pareja de fuerzas opuestas corriendo en ambas direcciones a la vez: es ese juego de oposiciones lo que mantiene unido el ensamblaje que Heráclito llamó ópuovía y que también rige la norma de vida de la polis (B 114).

A esta visión de la ley y de la vida cívica se une en Heráclito la abierta simpatía que sintió hacia la figura de Hermodoro, el único efesio que recibe del filósofo un trato favorable en algunos de los fragmentos que hemos conservado (explícitamente en B 121, implícitamente en B 33 y B 49). Lo desconocemos casi todo de la ejecutoria política de Hermodoro: lo único que sabemos con certeza es que su carrera, como hemos dicho más arriba, se vio truncada por el destierro, dictaminado con bastante probabilidad por la asamblea del pueblo de Éfeso. Así lo sugiere el fragmento B 121, que recoge la reacción indignada de Heráclito ante el destierro de su amigo, promulgado por los efesios "mayores de edad". La localización cronológica de este suceso es problemática, pero, sea cual sea, lo que está claro es que Hermodoro, "el más valioso de los efesios", representaba para su amigo Heráclito la posibilidad de implantar en Éfeso un sistema político-legal inspirado en (o no ajeno a) sus propias ideas. Que esto se hiciera "mediante el consejo de un solo hombre" (B 33) era lo de menos si redundaba en beneficio de la comunidad. Al parecer, esta promesa quedó sepultada con el exilio de Hermodoro y, si este legisló para los efesios, como declaran varios testimonios indirectos ${ }^{23}$, sus leyes fueron probablemente superadas por los acontecimientos ${ }^{24}$.

Hasta ahora, hemos estado traduciendo vónos por 'ley'. Pero, ¿es esta, en realidad, la acepción exacta de vó Debe tenerse en cuenta que la palabra vónos no se generaliza en su acepción de 'ley positiva' o 'escrita' antes de la mitad del s. V a.C. Por eso, parece especialmente acertada la definición de vó $\mu$ os que da Dilcher ${ }^{25}$ para cualquier comunidad política ( $\pi$ ó $\lambda ı s)$ anterior a esa fecha: "The totality of rules, customs and forms of behaviour that are valid and followed in one city". Si esto es así, entre las 'reglas' o 'normas' ("rules") debe haber leyes o procedimientos, sean

${ }^{23}$ Cf. supra, n. 18.

${ }^{24}$ No es este el lugar para discutir sobre la posible contextualización histórica de estos sucesos, asunto que ya hemos tratado en R. Caballero, "Las Musas jonias aprenden a escribir: ley escrita y tratado en prosa en los milesios y Heráclito”, Emerita 76, 2008, 1-31. Cf. también L. Senzasono, "Eraclito e la legge", Gerión 14, 1996, 53-75, y S. Mouraviev, Heraclitea, III 1. Héraclite d'Éphèse. Les vestiges. 1. La vie, la mort et le livre d'Héraclite, Sankt Augustin, 2003, 137-40. Lo que importa tener en cuenta es que la evolución política de Éfeso conoció impulsos democratizadores en tres períodos distintos de la vida de Heráclito: a) El estallido de la rebelión jonia, con la deposición de los tiranos y la instauración de regímenes isonómicos en las ciudades jonias (499-498 a.C., cf. Hdt. 5.38); b) La instauración de regímenes 'democráticos' por parte de Mardonio en Jonia una vez derrotada la rebelión antipersa (492 a.C., cf. Hdt. 6.43); c) La entrada de las ciudades jonias en la Liga ático-délica liderada por Atenas ( 478 a.C.).

${ }^{25}$ R. Dilcher, Studies in Heraclitus, Hildesheim 1995, 49. 


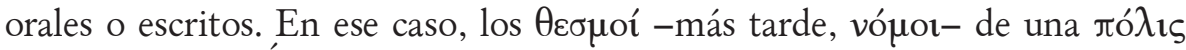
arcaica, como la Éfeso de inicios del siglo V a. C., forman parte de este sentido amplio de vónos, tal como lo usa Heráclito, y que podría traducirse como "norma de vida" o "norma y costumbre".

Si interpretamos en ese sentido amplio el término vópos de B 44, el fragmento no pierde un ápice de su fuerza y originalidad. Porque lo que está pidiendo Heráclito al pueblo de Éfeso es que, aun introduciendo cambios inevitables en aspectos particulares de la forma de vida de su ciudad, dictados por los nuevos tiempos y exigencias, el $\delta \tilde{\eta} \mu o s$, como fuerza social ascendente en el seno de la polis ${ }^{26}$, debe mantenerse fiel a las formas y usos tradicionales (vó ${ }^{\prime}$ os) en lo esencial, esto es, en todo lo que favorezca el mantenimiento de la unidad y cohesión de la comunidad. Solo así, piensa Heráclito, podrá

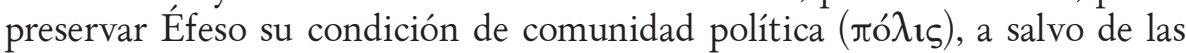
fuerzas destructivas que amenazan la integridad de su convivencia, como los enemigos amenazan la muralla común. Esas fuerzas pueden surgir en cualquiera de los grupos sociales que se disputan el poder en Éfeso, siempre que concentren demasiados privilegios o se impongan con abusos y violencia: desde la tiranía exclusivista hasta las aventuras revolucionarias del pueblo, pasando por los excesos de las familias nobles, el medio social al que pertenecía Heráclito.

Estamos convencidos de que Heráclito escribió algo en lugar de vंđè $\rho$

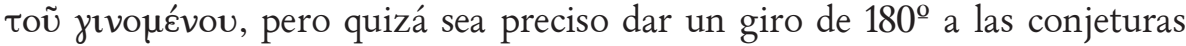
hasta ahora propuestas de ese sintagma. Nuestra aportación es la siguiente:

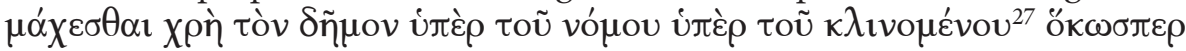

${ }^{26}$ En nuestra opinión, Heráclito deja en una calculada ambigüedad el sentido exacto de la palabra $\delta \tilde{\eta} \mu o \varsigma$ en este fragmento. Como es sabido, esta palabra a partir de su acepción de 'aldea' o 'distrito' donde vive el pueblo llano pasó a significar el estrato social popular, que, en esta época y cada vez con mayor fuerza, empezaba a ser un actor político diferenciado de la nobleza. Desde esta acepción se pasa al pueblo en el sentido de 'cuerpo de ciudadanos' con derechos políticos. Este último significado, más moderno, se generalizó con la difusión del modelo isonómico de Clístenes desde Atenas a otros estados griegos. Según Lledó, "La lucha por la ley", 262-8, este fragmento de Heráclito se sitúa precisamente en el punto de partida de este proceso que condujo, con la democracia, a la noción de ciudadanía compartida. Si el pueblo lucha por la ley como si fuera su propia muralla, es porque esa lucha por sí misma, destinada a defender la ley como mediación entre intereses divergentes, implanta un orden común y compartido en el que es posible el nacimiento de un $\delta \tilde{\eta} \mu o \varsigma$ que aglutine a todos los grupos y facciones de la polis. Nosotros compartimos en sus líneas generales este penetrante análisis de Lledó siempre que se aplique a un concepto ideal de $\delta \tilde{\eta} \mu o \varsigma$ que lucha por la ley, tal como piensa Heráclito que objetivamente debería hacerlo ( $\chi \rho \eta ́)$ el pueblo de Éfeso. De lo que no estamos tan seguros es de que Heráclito viera en el pueblo real de su ciudad una garantía de unidad y cohesión para la polis, como tampoco la veía en la tiranía ni en la aristocracia. No cabe duda de que la ley por la que debe luchar el pueblo es una "ley amenazada", como apunta Lledó ("La lucha por la ley", 264); la conjetura que proponemos aquí parte precisamente de ese supuesto. Pero la amenaza viene de la úßpis con la que nobles, tiranos y el pueblo mismo luchan por el poder, cuando esa lucha debería ser siempre por defender la ley común que hace la lucha posible.

${ }^{27}$ Hemos de confesar que, hasta donde sabemos, la plausibilidad paleográfica de la corrup- 


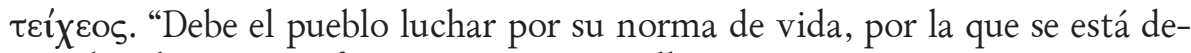
rumbando, como si fuera su propia muralla".

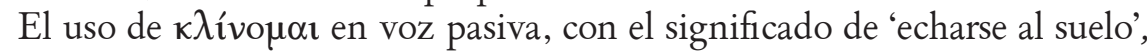

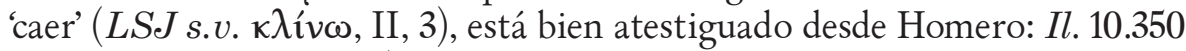

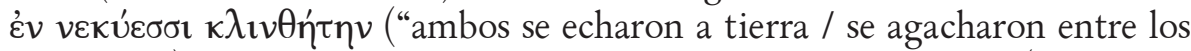

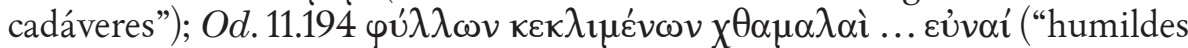
lechos ... de hojas caídas"). Otro uso propio de $\kappa \lambda i$ ivo $\mu \alpha$ con esta misma acepción lo encontramos en la Antígona de Sófocles (1188), donde Eurídice describe así el desmayo que le han causado los rumores de la muerte de su hijo

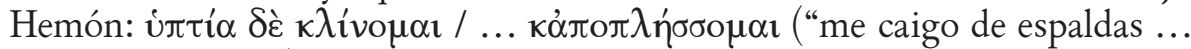
y me desvanezco"). Pero en Solón y Esquilo encontramos dos usos figurados, que evocan dramáticamente la caída estrepitosa de la tierra del Ática y la de Asia, en el primer caso por culpa de las guerras civiles, en el segundo tras la

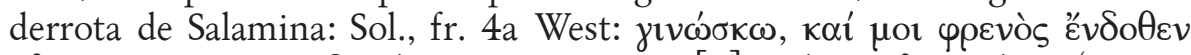

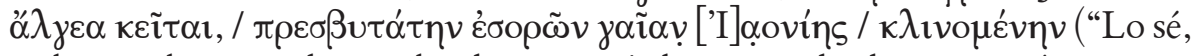
y dentro de mi pecho anidan las penas / al contemplar la tierra más antigua

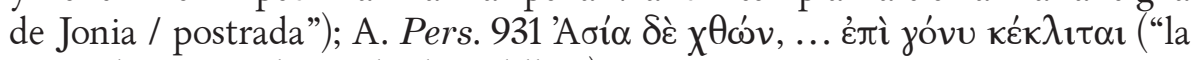
tierra de Asia ... ha caído de rodillas").

El uso que más nos interesa a nosotros está en el libro $\mathrm{V}$ de las Helénicas de Jenofonte, donde el rey espartano Agesípolis consigue inundar la muralla de Mantinea cortando el paso del río que atraviesa la ciudad. El resultado de

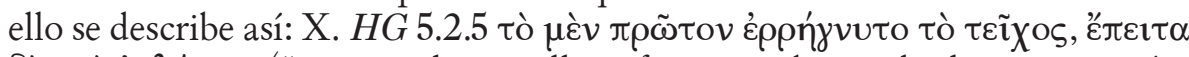

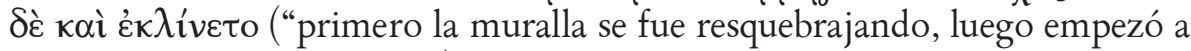
derrumbarse / desplomarse"). Pese a que Jenofonte es posterior a Heráclito, no tenemos razones para pensar que el verbo $\kappa \lambda$ ívo $\mu \alpha \mathbf{l}$ no tuviera en el dialecto jonio de Éfeso, a comienzos del s. V a.C., la misma acepción que posteriormente en ático ('caerse', 'derrumbarse', en sentido propio y figurado), ya que los usos homéricos y de la elegía, como hemos visto arriba, apuntan ya en esa dirección.

ción supuesta en este caso (el error de $\kappa \lambda_{\mathbf{t}}$ a a $\mathbf{\gamma}_{\mathbf{1}}$ ) no es nada transparente, y ello tanto si $\boldsymbol{\Omega}$, antepasado de BPF, era un códice en uncial como si era un ejemplar transliterado a la nueva minúscula bizantina del s. IX d.C. (cf. Dorandi, Laertiana, 102-5). De todos modos, este argumento, siempre deseable para respaldar cualquier conjetura, no resulta, en nuestra opinión,

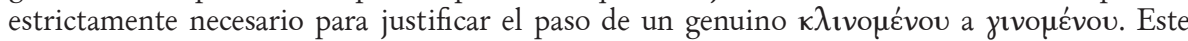
podría explicarse simplemente por obra de una asociación mental inconsciente con otra palabra mucho más corriente, muy similar en la forma ( ¡ıvoú́vov), que trivializaba el contenido del fragmento, pero no lo arruinaba, como hemos visto más arriba. Ya Vollgraff (cf. supra, n. 12) advirtió una acepción semejante, que aquí podría tener el verbo yíyvopor ("debido, adeudado", y de ahí "debido, apropiado"). A nosotros nos parece que la acepción más banal, y muy frecuente en griego tardío, de "normal, regular, acostumbrado", que deriva de aquella (cf. LSJ

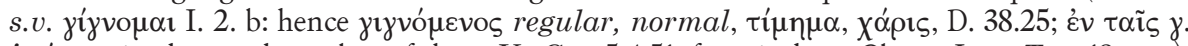
$\grave{\eta} \mu \varepsilon$ pars $_{\text {in }}$ the usual number of days, X. Cyr. 5.4.51; freq. in later Gk., as Luc. Tox. 18, etc.), ayuda a entender no el texto genuino de Heráclito, sino el origen de la lectio deterior (íđè ¡ıvof́́vou) que exhiben los manuscritos principales de Diógenes Laercio. 
La imagen plástica de una muralla desmoronándose: esa es la metáfora que, a nuestro juicio, podría haber elegido Heráclito en el fragmento B 44 para describir la dramática ruina de la norma de vida (vónos) de Éfeso, por la que el pueblo ha de combatir igual que lucharía por su propia muralla si esta se viniera abajo. Que el estilo y norma de vida de una ciudad se derrumbe como una muralla es una metáfora ciertamente novedosa, pero, en nuestra opinión, no es imposible ni disparatado que Heráclito se expresara así al contemplar la decadencia de las reglas y usos sociales tradicionales de Éfeso. Ya Solón, bastantes años antes, había empleado el mismo verbo cuando se quejaba de que el largo conflicto civil y la esclavitud de no pocos atenienses habían dejado la tierra más antigua de Jonia sumida en un penoso estado de postración y abatimiento ( $(\lambda \iota v o \mu \varepsilon ́ v \eta v)^{28}$.

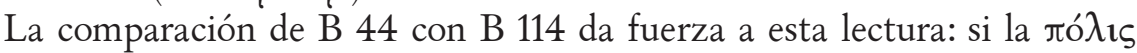

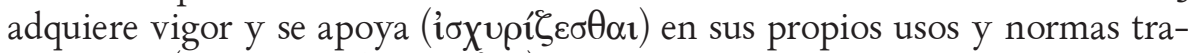

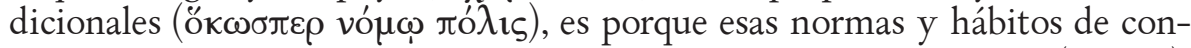
ducta, como todas las normas humanas, se alimentan de "una única (norma),

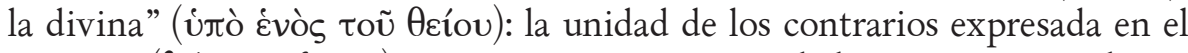
Discurso ( $\lambda$ ó $о$ os, cf. B 1). Es precisamente esa unidad entre intereses divergentes el bien último que es preciso proteger en la ciudad, como si fuese la muralla que salva a los ciudadanos de la destrucción. Para Heráclito, la fuerza

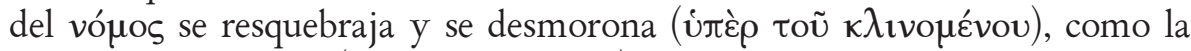

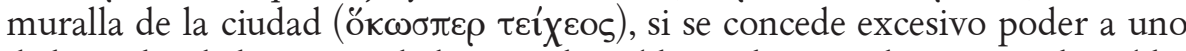
de los polos de la comunidad, ya sea la nobleza, el tirano de turno o el pueblo. Los fragmentos de Heráclito denunciando la üßprs (B 43) o llamando a la

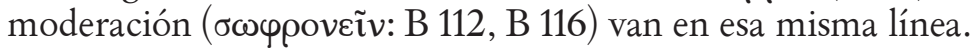

En B 44, Heráclito se dirige expresa y directamente al pueblo y le exhorta

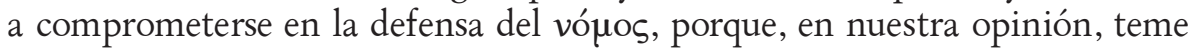
probablemente que el pueblo conquiste un protagonismo excesivo en la vida ciudadana y así se desequilibre la balanza de intereses contrarios que mantiene

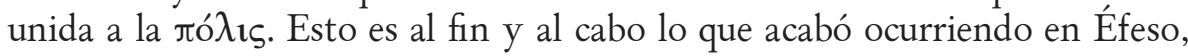
y lo que motivó probablemente el alejamiento definitivo de Heráclito de la política de su ciudad ${ }^{29}$. Uno de los jalones decisivos en esa deriva democrática de Éfeso fue el destierro de su amigo Hermodoro, por quien Heráclito entona un amargo lamento en B 121, al denunciar abiertamente la decisión tomada

${ }^{28}$ Es cierto que, en el caso de Solón, esta lectura reposa sobre el examen autóptico que hizo Wilcken del papiro Lond. 131, que conserva la Constitución de los atenienses de Aristóteles, el único testimonio del que disponemos para esta parte inicial del poema elegíaco de Solón (Ath. 5). Aunque hay otras conjeturas, esta es la que retienen casi todos los editores y

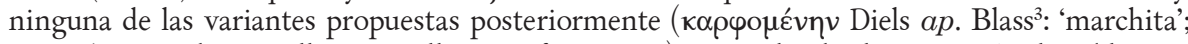

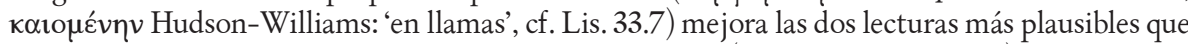

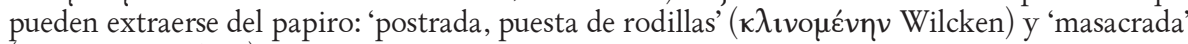

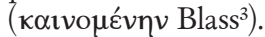

${ }^{29}$ Cf. D.L. 9.3. 
por la asamblea del pueblo. Como demuestra B 33, para Heráclito entraba dentro de los usos normativos (vónos) que el pueblo siguiera los consejos de un solo ciudadano si este era, como pensaba de Hermodoro, "el más valioso de los efesios" (B 121). En otro fragmento, Heráclito cuestiona implícitamente que el principio de la mayoría sea en sí mismo bueno en la toma de decisiones políticas: "Uno solo vale por diez mil, si es el mejor" (B 49).

Heráclito convoca, pues, al $\delta \tilde{n} \mu o \varsigma$ a defender el vónos aun a sabiendas de que es bastante improbable que lo haga. La actitud de Heráclito se asemeja en cierto modo a la que tuvo Solón frente a Pisístrato: el sabio ateniense sabía que, por su vejez y por la falta de apoyos, no podía hacer mucho contra la amenaza de tiranía que representaba su adversario. Pero no por ello dejó de sacar las armas a la puerta de su casa y recordar a los atenienses que él había cumplido con su deber de defenderse contra el tirano, mientras los exhortaba a hacer lo mismo ${ }^{30}$. Del mismo modo, nos resulta difícil imaginar a Heráclito callando ante el pueblo por pensar que no va a ser obedecido. Tampoco se callaba cuando se quejaba repetidamente de que la gente no sabía escuchar el Discurso del que se consideraba portavoz privilegiado (B 1). Que no tuviera muchas esperanzas de ser entendido por los $\pi$ o $\lambda \lambda$ oí no le impedía hacerse escuchar alto y claro.

El desafío de Heráclito consiste en alzar la voz contra la deriva democrática de Éfeso: lo que debe hacer el pueblo es justamente lo contrario de lo que está haciendo. Pues el desmoronamiento de la norma de vida de Éfeso estaba siendo propiciado por el pueblo mismo: la norma de vida es como la muralla de una ciudad, y luchar por ella es mantenerse fiel a lo que da fuerza a la comunidad (B 114). La exhortación de Heráclito, con ser clara y transparente, esconde dentro de sí un amargo reproche: la contradicción entre lo que el pueblo debería hacer objetivamente ( $\chi \rho)^{\prime}$ y lo que en realidad está haciendo. Para Heráclito, la necesidad de que el pueblo defienda la norma de vida de la polis se impone con la misma evidencia con la que cualquiera de sus ciudadanos reconocería que el pueblo debería luchar por la muralla que está siendo

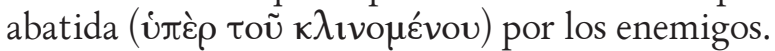

Pero lo trágico de la paradójica situación que denuncia Heráclito en este fragmento es que la norma de vida de Éfeso está siendo derribada, como si fuera su propia muralla, y el pueblo no solo no está haciendo nada para evitarlo, sino que es suya la responsabilidad de que se derrumbe definitivamente. Esta relación paradójica entre el llamamiento de Heráclito y el contexto pragmático en el que se inserta no es solo resultado de una hipótesis historiográfica verosímil, que se deriva de la lectura cruzada que hemos hecho arriba de este texto con otros fragmentos políticos ${ }^{31}$. Creemos que, a su modo, Heráclito sugiere implícitamente esa misma paradoja jugando con la polisemia

${ }^{30}$ Arist. Ath. 14.2.

${ }^{31}$ Para el contexto histórico-político de los fragmentos de Heráclito, cf. supra, n. 24. 
de $\kappa \lambda \imath$ ıoućvov: si la norma de vida de Éfeso "se está derrumbando" como si fuera su propia muralla es porque "se está desviando / escorando" peligrosamente hacia uno de los polos de la vida cívica en detrimento de los demás. Para el vónos, desviarse fuera de su camino es sinónimo de derrumbe, igual que la muralla se viene abajo si se inclina fuera de la vertical.

Esta otra acepción de la voz pasiva de $\kappa \lambda i ́ v o \mu \alpha \mathbf{~ ( ' i n c l i n a r s e ' , ~ ' d e s v i a r s e ' ~}$

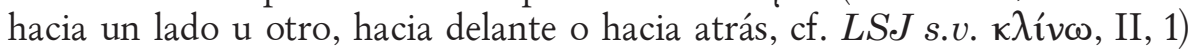
está bien establecida en la poesía griega. En Homero y Hesíodo designa el giro decisivo que desequilibra la batalla: cf. $I l .19 .223$ (en voz activa factitiva)

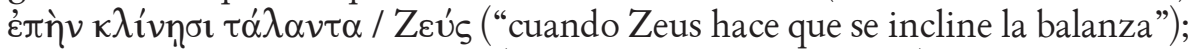

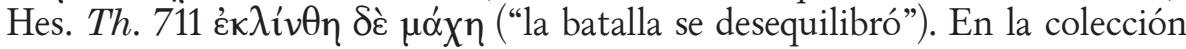
teognidea, el tesoro de la elegía arcaica, los usos de esta acepción de $\kappa \lambda$ ívo $\mu \alpha$ se aplican a contextos políticos y representan el desequilibrio del juego cívico: la equidistancia del poeta frente a las facciones enfrentadas en su ciudad es

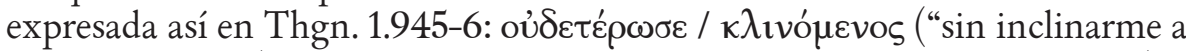
uno y otro lado") 32 ; a su vez, la polis es comparada a una "nave a la deriva" (cf.

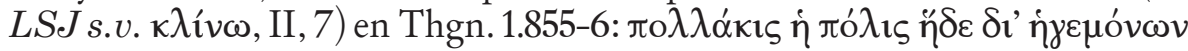

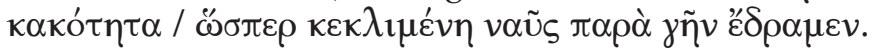

Aunque es difícil establecerlo con seguridad a tanta distancia de los hechos evocados por Heráclito en el trasfondo histórico de B 44, no me parece improbable que las dos acepciones de $\kappa \lambda$ ívouol resonaran ambiguamente en

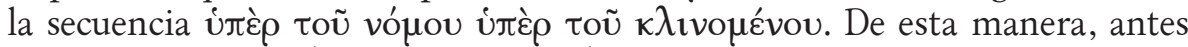

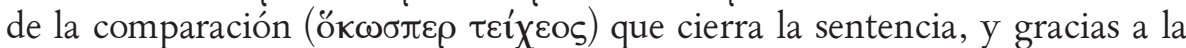

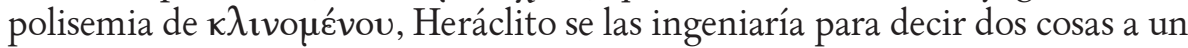
tiempo: "el pueblo ha de luchar por su norma de vida, por la que 'se está tambaleando' (es decir, 'amenaza derrumbe')", y "el pueblo ha de luchar por su norma de vida, por la que 'se está tambaleando' (es decir, 'se desvía', 'se escora', 'va a la deriva')". Por supuesto, la comparación con la muralla desambigua el mensaje en favor de la primera opción, pero, a un nivel más profundo de lectura, mantiene el eco y la conexión entre las dos acepciones de $\kappa \lambda$ ívo $\mu \alpha \mathbf{l}^{33}$ : es la 'deriva' política protagonizada por el pueblo la que propicia el 'derrumbe' de la norma de vida de Efeso, y el pueblo, si de verdad quiere conservar la integridad física y moral de la polis, está obligado a combatir en defensa de esa norma y costumbre que por su culpa está siendo amenazada.

32 Aunque no es seguro que formen un solo cuerpo, este dístico suele editarse en unión con

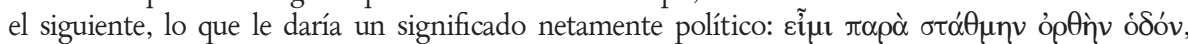

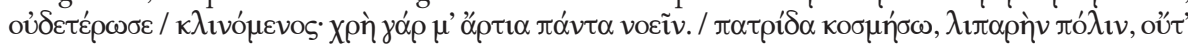

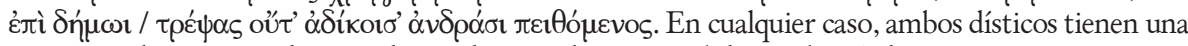
impronta claramente soloniana, hasta el punto de que Bergk los atribuyó al poeta ateniense.

${ }^{33}$ La polisemia creadora de ambigüedad es un recurso ampliamente utilizado por Heráclito en los fragmentos. Mouraviev la ha llamado "polifonía léxica": véase un inventario de este recurso en S. Mouraviev, Heraclitea, III.3.A. Recensio. Fragmenta: le langage de l'Obscur. Introduction à la poétique des fragments, Sankt Augustin 2002, 374. 


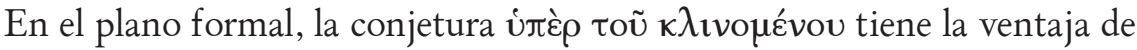
resolver de un plumazo las restantes dificultades que, como señalábamos al principio, el fragmento plantea en la versión transmitida por los manuscritos de Diógenes Laercio:

1. Convierte en irrelevante el dilema de escoger entre las dos variantes del sintagma comparativo, ambas avaladas por manuscritos de Dióge-

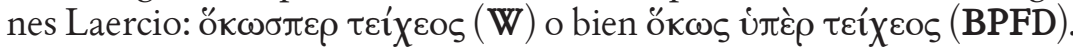
Esta última variante, aun dando el texto de $\boldsymbol{\Omega}$, tiene el aire de una lec-

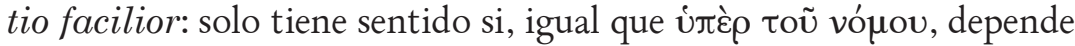

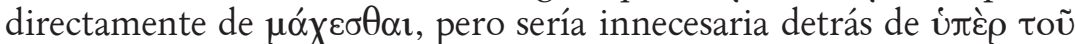

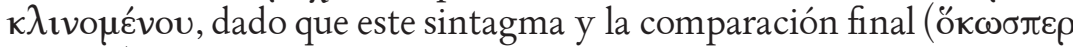
$\tau \varepsilon i ́ x \varepsilon o \varsigma)$ se iluminan recíprocamente sin necesidad de añadir nada. A

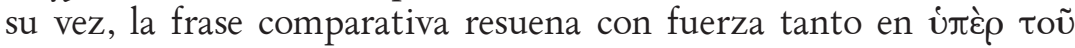

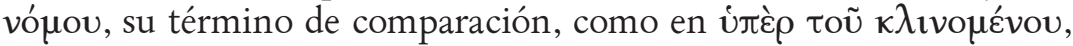
produciendo un tipo de "polifonía" sintáctica que hemos tratado de reflejar en nuestra traducción, adoptando la división en kola de Mouraviev $^{34}$ :

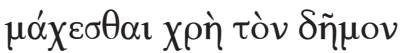

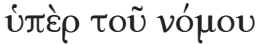

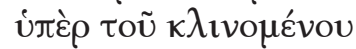

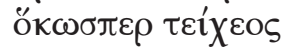

"Debe el pueblo luchar por su norma de vida por la que se está derrumbando tal que fuera su muralla".

2. Como puede verse, y pese a que ello no tiene fuerza probatoria en sí misma, nuestra lectura es asimismo atendible desde el punto de vista estilístico: el fragmento consta de cuatro kola que, por su número de sílabas (7-5-7-5), presenta una estructura ABAB. En cambio, la

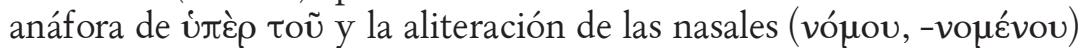
sirven para 'soldar' los dos miembros centrales en un crescendo que desciende abruptamente hasta la comparación final. Si leemos ìjè $\rho$

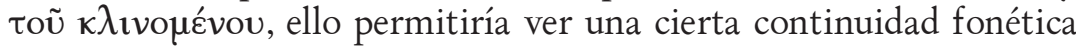
(aliteración de $\kappa$ y repetición de $-\pi \varepsilon \rho$ ) entre el tercer y el cuarto miembro, lo que facilita la transición hacia el motivo de la muralla. Además, los motivos de la lucha y de la muralla abren y cierran en anillo

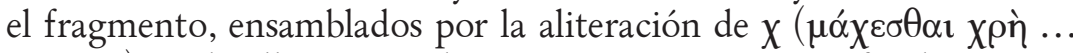

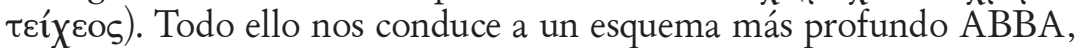
que se superpone y contrasta con la estructura, más superficial, basada en la isosilabia de los kola.

${ }^{34}$ Para la estructura "silabotónica" de B 44, cf. Mouraviev, Heraclitea, III.3.A: le langage de l'Obscur, 241. 
